\title{
Microstructure evolution and fracture behaviour for electron beam welding of Ti-6Al-4V
}

\author{
WU HUIQIANG*, FENG JICAI and HE JINGSHAN \\ State Key Laboratory of Advanced Welding Production Technology, Harbin Institute of Technology, \\ Harbin 150001, P.R. China
}

MS received 30 September 2003; revised 1 March 2004

\begin{abstract}
The effect of microstructural characteristics on fracture behaviour mechanism for electron beam welding of Ti-6Al-4V was investigated. The results indicated that the welded microstructure composed of coarse needle $\alpha+\beta$ phases presenting disordered and multidirectional short needle morphology to make fracture mechanism complex. The coarse grains in weld seam with microhardness $536 \mathrm{HV}$ were easy to be fractured in the region where welding heat input was $\geq 68.8 \mathrm{~kJ} / \mathrm{m}$. There exists flat curves of Ti, Al and $\mathrm{V}$, Fe concentration distribution fluctuation to cause microstructural amplitude-modulated decomposition to increase the joint ductility and cleavage strength. The uneven distribution of the partial micropores located at the interior of the specimen acting as crack initiation sites lead to non-linear branch propagating path. The $\alpha+\beta$ interlaced structure results in the fracture location near $\alpha / \beta$ interface. The existence of stacking fault structure caused pile-up of dislocation to produce micropores to be new fracture initiation sites.
\end{abstract}

Keywords. Electron beam welding; microstructure evolution; fracture behaviour; titanium alloy.

\section{Introduction}

Ti-6Al-4V alloys with excellent specific tensile and fatigue strengths and corrosion resistance have been mainly used for aircraft structural and engine parts, materials for petrochemical plants and surgical implants (Messler 1981; Jinkeun 2003). However, it is apparent that the ability to weld these materials to themselves and to other materials is the key to making them more attractive. With the development of titanium alloy industries, many welding methods such as tungsten inert gas welding (TIG), plasma welding, electron beam welding and diffusion welding have already been developed (Irving 1994; Keshava Murthy and Sundaresan 1998; Qi et al 2000). Because of their high chemical activity, titanium alloys readily absorb harmful gases (oxygen, hydrogen and nitrogen) and many problems such as low mechanical properties and unstable structures would appear. High vacuum electron beam welding (EBW-HV), which offers a number of advantages and characteristics such as high energy density, narrow heat scope, rapid cooling rate over conventional joining process can protect joints from gaseous contamination (Dance 1995).

In the present study, a Ti-6Al-4V alloy sheet was welded by electron beam welding, and the microstructure characterization and fracture behaviour of the welded region were investigated and compared with the base metal.

\footnotetext{
*Author for correspondence
}

Effect of welded microstructure on microhardness, tensile and fracture properties were analysed, and microstructural factors occurring at $\alpha, \beta$ phase and at interfaces between them were examined by observing fracture surfaces. Since these experiments allow direct comparison and analysis of the fracture propagation behaviour, it is expected to contribute to fundamental understanding of the fracture mechanism and the role of interface for providing a scientific basis for welded structure design, manufacturing and safety estimation.

\section{Experimental}

The material used in this study was a $1.5 \mathrm{~mm}$ thick sheet of Ti-6Al-4V alloy. Its composition and thermophysical mechanical properties are shown in table 1.

Before welding, the specimens were mechanically ground with 120 grit $\mathrm{SiC}$ paper, followed by pickling in a solution composed of $400 \mathrm{ml} \mathrm{H} \mathrm{H}_{2} \mathrm{O}+40 \mathrm{~g} \mathrm{KOH}+40 \mathrm{ml} \mathrm{H}_{2} \mathrm{O}_{2}$ in order to remove surface contaminants. All welding experiments were performed using MEDARD45 model pulsed electron beam welding machine. The degree of vacuum in EBW corresponded to $1.33 \times 10^{-3} \mathrm{~Pa}$, and the weld heat input $(E)$ in the test was $34.4 \mathrm{~kJ} / \mathrm{m}, 48.0 \mathrm{~kJ} / \mathrm{m}$ or $68.8 \mathrm{~kJ} / \mathrm{m}$. The welded samples were sectioned into metallographic specimens. These metallographic samples were prepared using conventional metallographic procedures used for titanium alloys. After the specimens were etched by a Kroll solution $\left(\mathrm{H}_{2} \mathrm{O} 100 \mathrm{ml}\right.$, $\mathrm{HF} 3 \mathrm{ml}$, and $\mathrm{HNO}_{3}$ $5 \mathrm{ml}$ ), microstructural characterization was performed 
using light $n$ (SEM) equipr metry (EDS) (TEM). X-ray phase identifi sy, scanning electron microscopy energy dispersive X-ray spectroransmission electron microscopy tion (XRD) was used for primary $\mathrm{f}$ the fusion zone and base metal.
Measurement parameters for XRD were as follows: $\mathrm{Cu}$ $\mathrm{K} \alpha$ radiation, accelerating voltage $40 \mathrm{kV}$, and tube current $150 \mathrm{~mA}$. Diffraction patterns were obtained in the step, $2 \theta$ mode in the range of $20-100$ degree. Microhardness data was obtained using a microhardness tester

Chemical composition and thermophysical mechanical properties of $\mathrm{Ti}-6 \mathrm{Al}-4 \mathrm{~V}$.

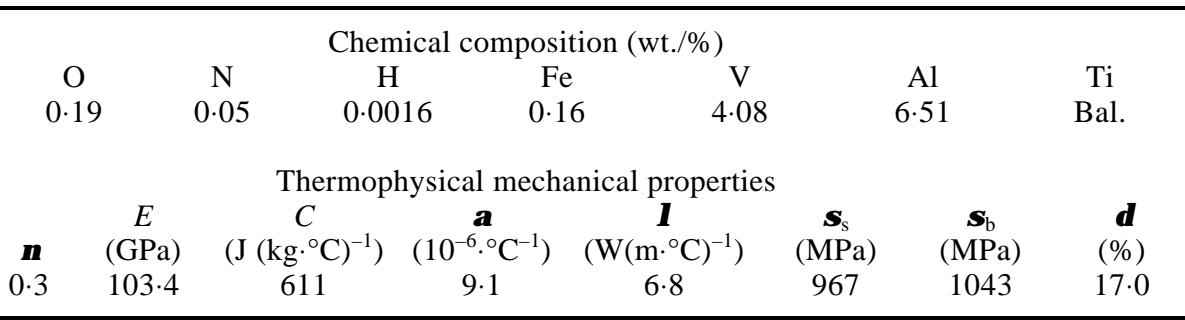

$* \rho$, density; $v$, poisson ratio; $E$, Young's modulus; $C$, specific heat; $\alpha$, coefficient of thermal expansion; $\lambda$, coefficient of heat conductivity; $\sigma_{\mathrm{s}}$, yield strength; $\sigma_{\mathrm{b}}$, ultimate strength; $\delta$, elongation.

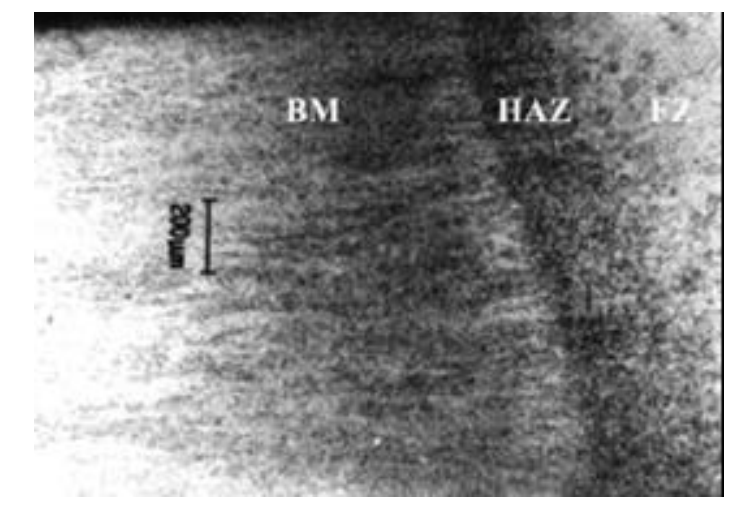

Figure 1. Low-magnification optical micrograph of EB welded regions of $\mathrm{Ti}-6 \mathrm{Al}-4 \mathrm{~V}$.
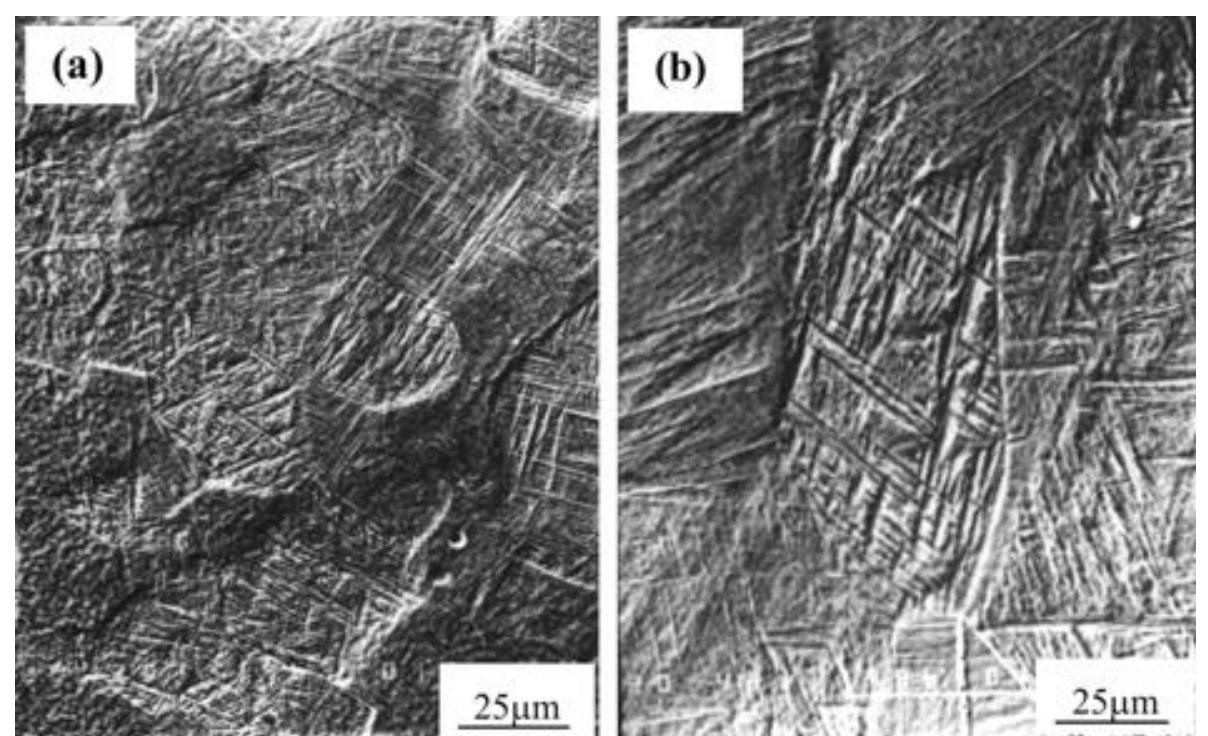

Figure 2. SEM secondary electron image of fusion zone microstructure in different weld heat inputs: (a) equiaxed grain morphology when $E=34.4 \mathrm{~kJ} / \mathrm{m}$ and (b) columnar grain in fusion zone when $E=68.8 \mathrm{~kJ} / \mathrm{m}$. 

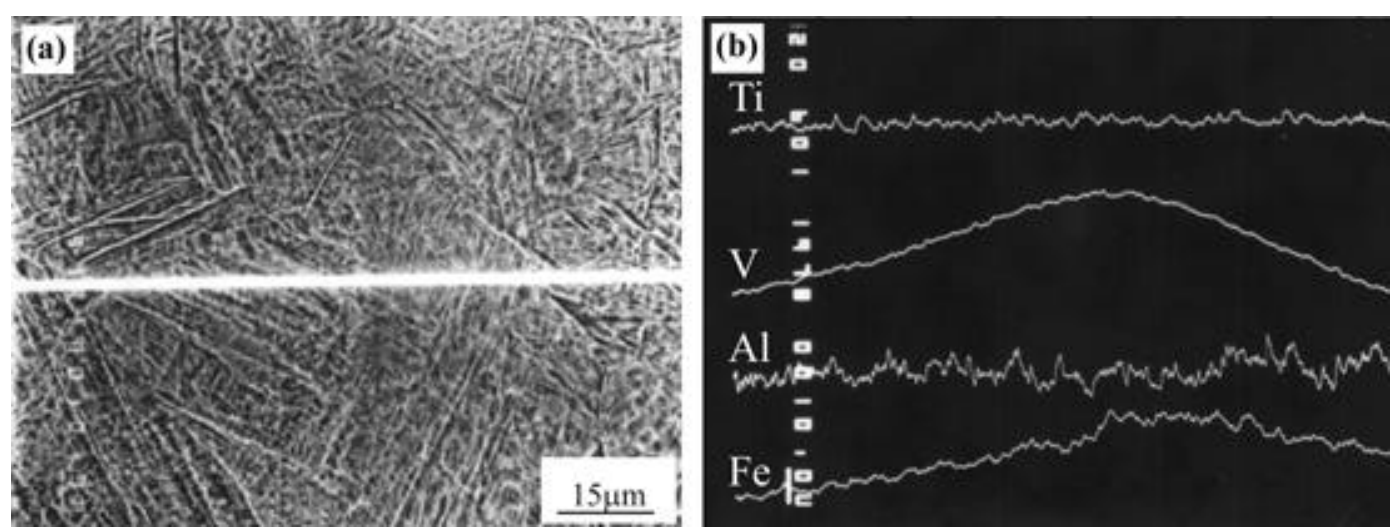

Figure 3. The interface of the weld and heat affected zone (a) and Ti, V, Al, Fe elements linear distribution (b).

with a load of $200 \mathrm{~g}$, load time $10 \mathrm{~s}$. Tensile tests were carried out on a universal testing machine at room temperature. Two tensile specimens were evaluated: one that consisted of only base metal and the other of only the fusion zone.

\section{Results and discussion}

\subsection{As-welded microstructural characterization}

Figure 1 is a low-magnification optical micrograph showing a cross-section of $\mathrm{Ti}-6 \mathrm{Al}-4 \mathrm{~V}$ plate. The microstructure of the base material consisted of equiaxed $\alpha$ grains within $\alpha$ grain boundary network of the $\beta$ phase, the latter being small in amount on account of the low manganese content in the alloy (Keshava Murthy and Sundaresan 1998). The fusion zone (FZ) of EB weld being quite narrow, formed in 2-4 mm width, and is clearly distinguished from the base metal. The evolution of microstructure from the base metal to fusion zone is evident. The figure shows that the fusion zone microstructure was composed of columnar grains oriented perpendicular to the direction of the radial fusion boundary. A region of about $200 \mu \mathrm{m}$ between the base metal and the fusion zone can be recognized as the heat affected zone (HAZ).

With increasing weld heat input, the sizes of grains in the fusion zone shown in figure 2 were found to vary from equiaxed morphology to columnar grain. This difference can be attributed to the difference in temperature gradients and solidification rates at different weld heat inputs. As the beam current was increased, the volume fraction of lamellar structure increased while that for the equiaxed grains decreased. The coarse grains lead to embrittle microstructure to deteriorate the joint performance.

Chemical composition profiles for $\mathrm{Ti}, \mathrm{V}, \mathrm{Al}, \mathrm{Fe}$ elements were examined by electron probe micro-analysis (EPMA) from the weld to heat affected zone (figure $3 \mathrm{a}$ ). As seen

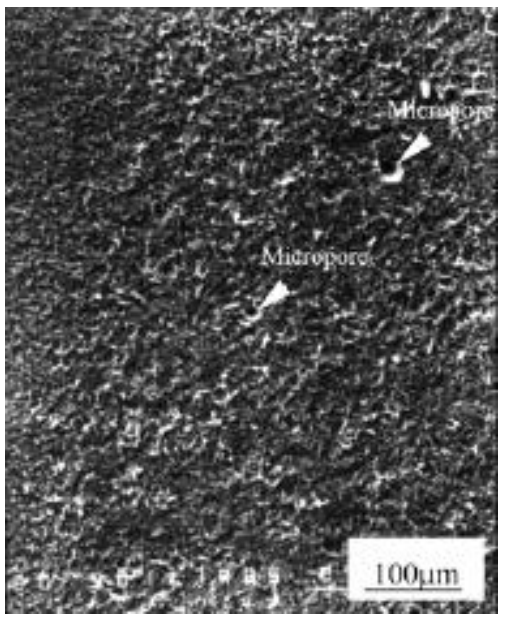

Figure 4. The existence of micropore.

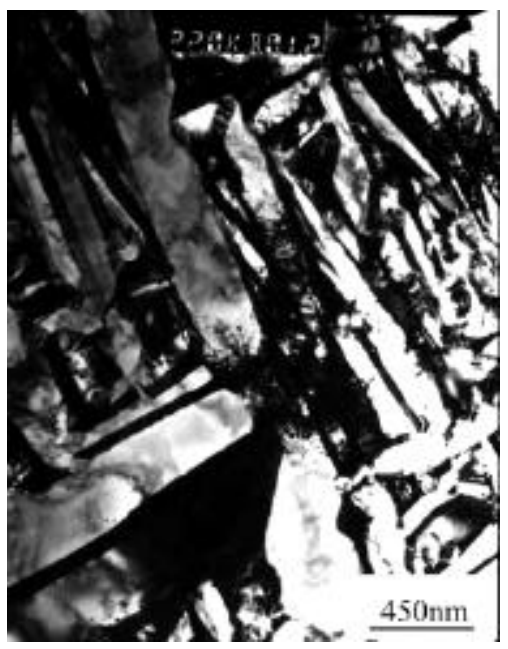

Figure 5. TEM micrograph of the EB weld.

from figure $3 b$, there exists flat curves for $\mathrm{Ti}$ and $\mathrm{Al}$ and $\mathrm{V}, \mathrm{Fe}$ concentration distribution fluctuation is attributed to phase constituents change in FZ and HAZ. According 


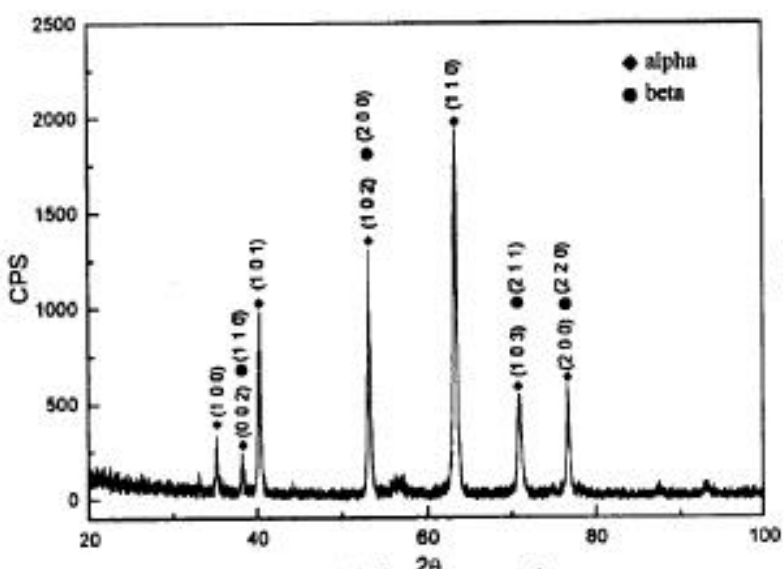

(a) base metal

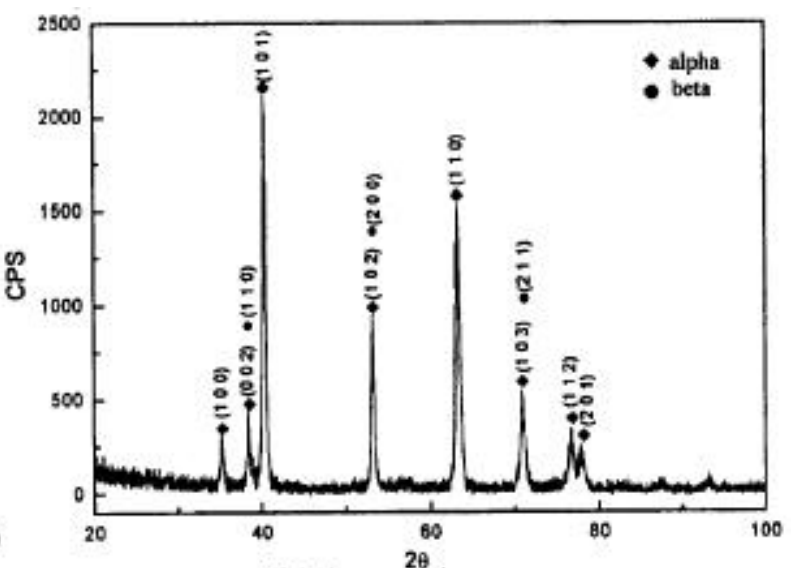

(b) the weld

Figure 6. X-ray diffraction pattern of the base metal and the weld.

to our earlier studies, it was found that $\alpha$ or $\beta$ phase had different elements in Ti-6Al-4V base material: $\alpha(\mathrm{Al} 6.7$ at. $\%$, $\mathrm{V} 2.8$ at. \%) and $\beta(\mathrm{Al} 5.1$ at.\%, V 13.1 at.\%). Elements content difference in both phases and phase constituents change of electron beam welding joint caused the line element distribution fluctuation from FZ to HAZ in total. Based on the unbalanced distribution of $\mathrm{V}, \mathrm{Fe}$ elements, $\beta$ phase distributed along $\alpha$ grain boundary was amplitude-modulated and decomposed into $\beta+\beta^{\prime}$ double phases (Chen et al 1999; Han et al 1999). The existence of both phases caused to increase the joint ductility and cleavage strength.

The distribution of micropores formed in EB welds is shown in figure 4 . The micropores seem to have arisen from low vacuum during EB welding or from poor cleanliness of the base metal surface. Micropores of size smaller than $5 \mu \mathrm{m}$ are generally found for using welding heat input $\geq 68.8 \mathrm{~kJ} / \mathrm{m}$. The presence of these micropores reduces elongation and tensile strength of EB welds, at the same time fracture cracks initiate at the surface or at large micropores located just beneath the surface, while other micropores located at the interior region of the specimen also act as crack initiation sites. The uneven distribution of the partial micropores located at the interior of the specimen acting as crack initiation sites lead to non-linear branch propagating path.

Figure 5 is a bright-field TEM micrograph of the fusion zone showing randomly oriented and multidirectional lamellar grains, which made fracture mechanism complex. This transformation results from the formation of $\beta$ phase when the composition of martensite approaches close to that of $\alpha$ phase and from the precipitation of $\alpha$ phase inside the $\beta$ phase (Jinkeun 2003). The existing interlaced structure has important influence on the fracture propagation behaviour.

\subsection{X-ray diffraction analysis of the fusion zone}

XRD was utilized to determine the different phases that developed in the fusion zone microstructure. Figure 6 shows

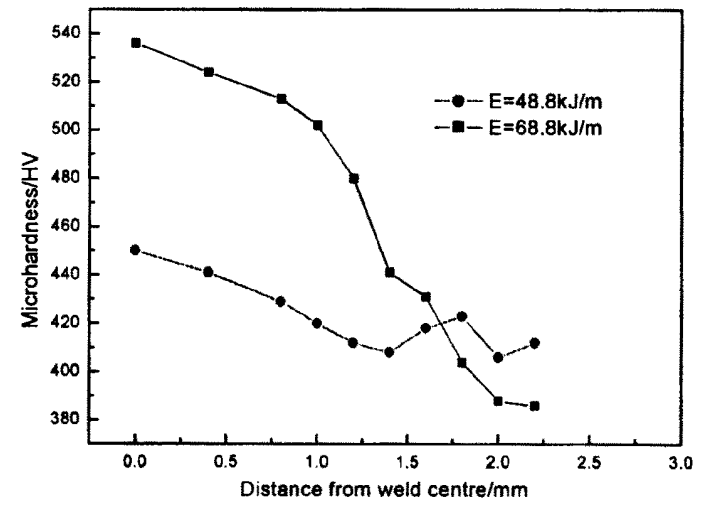

Figure 7. Microhardness distribution from weld centre.

the results for the base metal and the weld obtained at $E=48.0 \mathrm{~kJ} / \mathrm{m}$. The XRD data indicated an increase in the $\alpha$ phase, especially the main peak in the $\left(\begin{array}{lll}1 & 0 & 1\end{array}\right)$ crystal plane and a decrease in the $\beta$ phase, exhibiting the main peak in the $\left(\begin{array}{lll}2 & 0 & 0\end{array}\right)$ lane. In this case, for slow cooling speed the $\beta$ phase completely transformed into a well-defined $\alpha$ phase during high temperature stagnant stage. The amount of $\alpha$ phase in the fusion zone was increased to enhance the microhardness distribution.

\subsection{Microhardness measurements}

A microhardness profile of the as welded condition using different heat inputs is shown in figure 7. In this figure, the fusion zone microhardness $(536 \mathrm{HV})$ increased dramatically relative to the base metal microhardness of $400 \mathrm{HV}$ when using welding heat input equal to $68.8 \mathrm{~kJ} / \mathrm{m}$. The hardening of the weld zone with peaking at its centre may be attributed to the difficulty of slip in the extremely fine, lamellar intragranular. However, with middle welding heat input which has not caused heavy grain coarsening, the microhardness distribution was relatively smooth and even. 

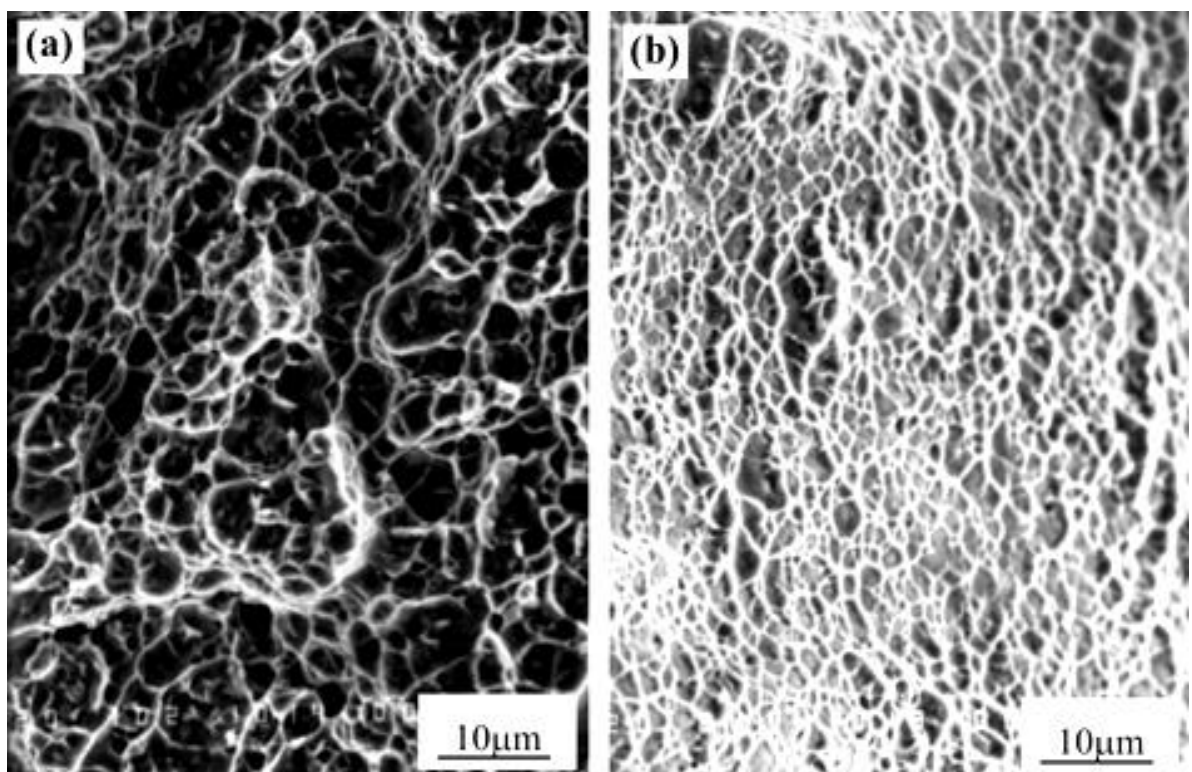

Figure 8. SEM fractographs of tensile specimens of (a) base metal and (b) EB weld.

\subsection{Fracture behaviour mechanism}

The observed tensile behaviour of the alloy in the as-welded condition agrees with the increase in fusion zone microhardness discussed previously. The reduction of mechanical properties can be partially explained by the microstructural changes that occur during welding that resulted in the large prior- $\beta$ grain size and a microstructure of high aspect ratio. Figures 8(a) and (b) are SEM micrographs of the tensile test fracture surfaces for the base metal and as-welded specimens, and show a ductile fracture mode composed of fine dimples, whose size decreases in the order of the base metal and EB weld. The electron beam weld fractured completely in transgranular manner (as shown in figure 9), which is associated with a greater degree of plastic deformation experienced at the crack tip and ligament formation, often yielding higher toughness.

\section{Conclusions}

(I) The welded microstructure was composed of coarse needle $\alpha+\beta$ phases presenting disordered and multidirectional short needle morphology to make fracture mechanism complex. The weld seam coarse grain with microhardness $536 \mathrm{HV}$ for using welding heat input $\geq 68.8 \mathrm{~kJ} / \mathrm{m}$ enhancing microstructure brittleness makes it easy to fracture in the region.

(II) From the weld to heat affected zone there exists flat curves of $\mathrm{Ti}, \mathrm{Al}$ and $\mathrm{V}, \mathrm{Fe}$ concentration distribution fluctuation to cause microstructural amplitude-modulated

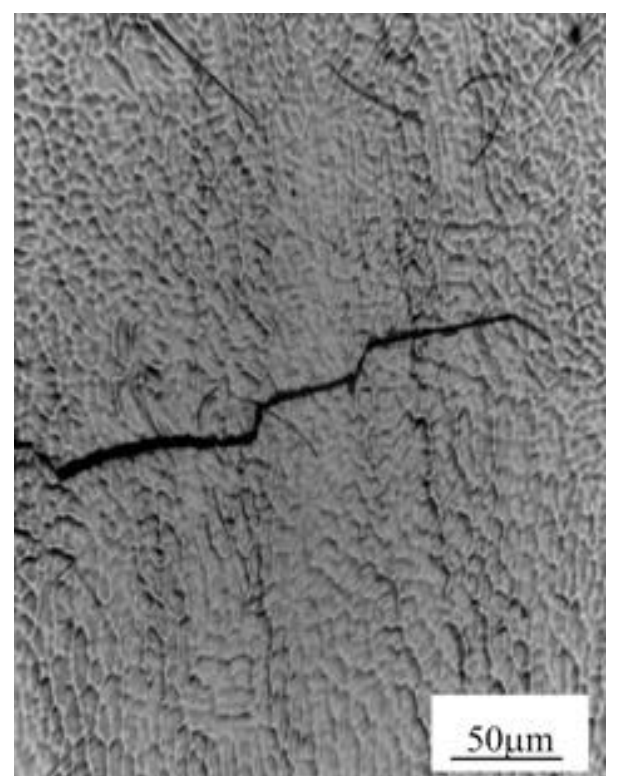

Figure 9. The weld fractured in transgranular manner.

decomposition to increase the joint ductility and cleavage strength.

(III) The uneven distribution of the partial micropores located at the interior of the specimen acting as crack initiation sites lead to non-linear branch propagating path. The $\alpha+\beta$ interlaced structure results in the fracture location near $\alpha / \beta$ interface because of the difference of both phases in thermal expansion coefficient. The existence of stacking fault structure caused pile-up of dislocation to produce micropores to be new fracture initiation sites. 


\section{Acknowledgement}

The authors wish to acknowledge the financial support provided by the National Science Foundation under grant number 2002AA305402 for this work.

\section{References}

Chen Xiaofeng, Han Zhong and Lou Xinfang 1999 Trans. Nonferrous Met. Soc. China 9535
Dance B G I 1995 Weld Res. 4119

Han Zhong, Lin Haochao and Chen Xiaofeng 1999 J. Chinese Electron Microsc. Soc. 18536

Irving Bob 1994 Weld. J. 7331

Jinkeun Oh, Nack J. Kim and Sunghak Lee 2003 Mater. Sci. Eng. A340 232

Keshava Murthy K and Sundaresan S 1998 J. Mater. Sci. 33 817

Messler R W 1981 Weld. J. $6079 \mathrm{~S}$

Qi Yunlian, Deng Ju and Hong Quan 2000 Mater. Sci. Eng. A280 177 